\title{
A Mathematical Sustainable Development Model
}

\author{
Shaohua $\mathrm{Wu}^{1, \mathrm{a}}$ \\ ${ }^{1}$ School of Control and Computer, North China Electric Power University, Baoding 071000, China; \\ awuwushaohuahua@163.com
}

Keywords: Analytic Hierarchy Process, Sustainable Development

\begin{abstract}
To construct an evaluation system to define when and how a county is sustainable or unsustainable, we describe metrics in eight aspects: health human, food security, access to clean water, local environmental quality, energy access, livelihoods, community vulnerability, and equitable sustainable development. An analytic hierarchy process (AHP) Model is established to get the grade of each country, and we use this grade to measure the sustainability level of Madagascar. We obtain three unsustainable indexes, including human health, food security and livelihoods with this method. Aiming at three unsustainable indexes, we put forward seven specific policies, which contain establishing hospitals, investing medical capital, introducing advanced agricultural technologies, importing food jobs and job trainings, providing education and providing minimum living guarantee. The implementation of policies is divided into four stage, which means four five-year plans are made. We identify the differences between there is a plan and get intuitively the effect degree of every policy. All in all, we clearly evaluate the effect our 20year sustainability plan has on sustainability level of Madagascar.
\end{abstract}

\section{Introduction}

Sustainable development is defined by the 1987 Brundtland Report as "development that meets the needs of the present without compromising the ability of future generations to meet their own needs." The United Nations (UN) predicts the world's population will level at 9 billion people by 2050. This, coupled with increased consumption, places a significant strain on the earth's finite resources. International aid agencies, planners, governments, and non-profit organizations are committed to construct an evaluation system for sustainable development. Therefore, striving towards a sustainable future has never been more imperative.

\section{AHP Model for the Sustainability of a Country}

According to the definition of sustainable development and the principle of evaluation indexes, we finally select eight indexes to develop an evaluation system, which are contains health human, food security, access to clean water, local environmental quality, energy access, livelihoods, community vulnerability, and equitable sustainable development. To get a measure to distinguish more sustainable countries from less sustainable countries, we use analytic hierarchy process (AHP) to conduct evaluation [2].

The four hierarchy structure is shown in following chart. 


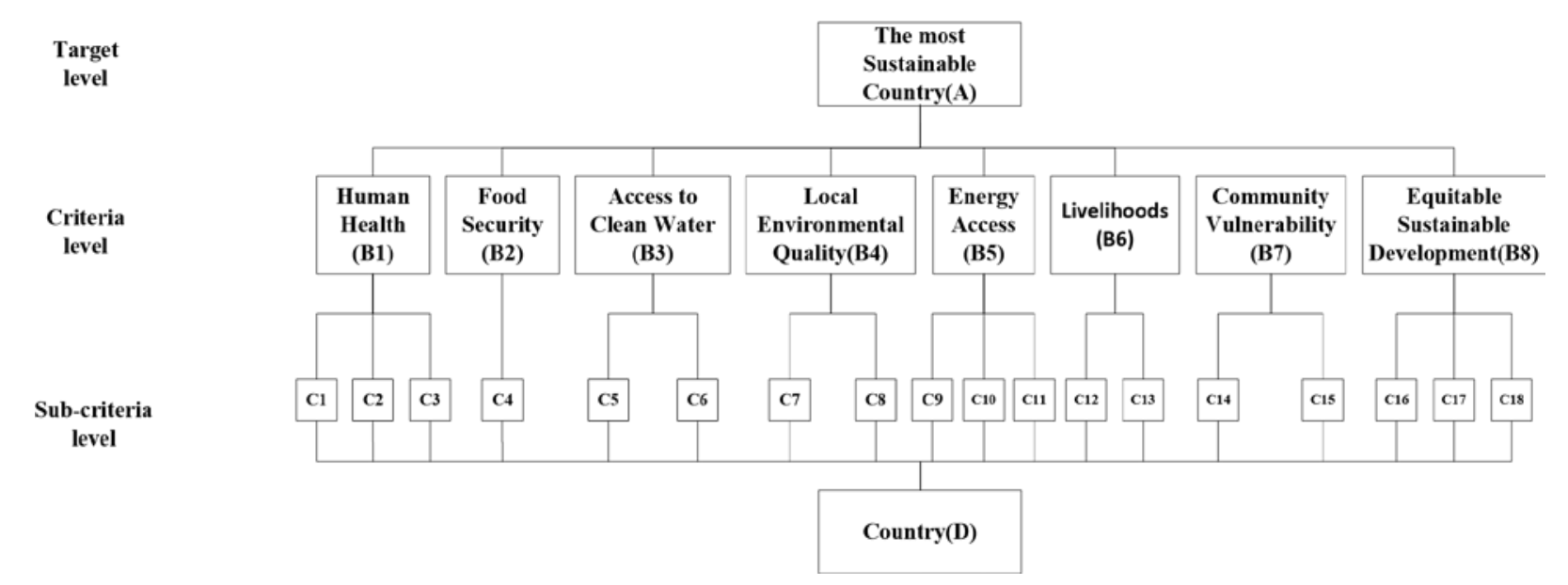

Fig. 1 The chart of hierarchical structure

The codes of 18 secondary metrics are shown in the following table.

Table 1 The code of 18 sub-indexes

\begin{tabular}{|c|c|c|c|}
\hline C1 & Health expenditure per capita & C10 & Combustible renewables and waste \\
\hline $\mathrm{C} 2$ & Improved sanitation facilities & C11 & Alternative and nuclear energy \\
\hline C3 & Life expectancy at birth & C12 & Unemployment \\
\hline $\mathrm{C} 4$ & Global food safety index & C13 & $\begin{array}{l}\text { Poverty headcount ratio at } \$ 1.25 \text { a } \\
\text { day }\end{array}$ \\
\hline C5 & Improved water source, rural & C14 & Incidence of tuberculosis \\
\hline C6 & Improved water source, urban & C15 & Prevalence of HIV \\
\hline C7 & Forest area & C16 & Income share held by lowest $20 \%$ \\
\hline C8 & Emissions & C17 & Income share held by highest $20 \%$ \\
\hline C9 & GDP per unit of energy use & C18 & Ecological footprint \\
\hline
\end{tabular}

\section{The 20 Year Sustainable Development Plan for Madagascar}

We select Madagascar as our research object, and obtain three unsustainable indexes by AHP [3]. Three unsustainable indexes are human health, food security and livelihoods. Aiming at the three unsustainable indexes, we make a 20 year plan that is divided into four Stage to move Madagascar towards a more sustainable future [4]. We make seven specific policies to improve the sustainable development of Madagascar. The implementation of policies is divided into four stage, namely we make four five-year plans. According to the actual conditions of Madagascar, we make our first five-year plan [5].

Policy 1: Establish Hospitals. We plan to establish 10 hospitals every year. The ratio of malnourished reduced one percent, and the life of national population increase 0.15 year on average. (Assuming that 10 hospitals can treat 30000 people and the cure rate is 80 percent, 10 percent of people in hospital is teenagers and one-third malnourished teenagers is cured, and the life of one-sixth people can increase 1.5 year on average after treatment.)

Policy 2: Invest Medical Capital. One million dollars is putted in medical capital, which can make the ratio of malnourished teenagers reduce 0.5 percent. (Assuming that every one million 
dollars investment can increase 20 percent of people in hospital, 10 percent of people in hospital is teenagers, and one-third malnourished teenagers is cured.)

Policy 3: Introduce Advanced Agricultural Technologies. We put 50000000 dollars in the primary industry every year, the proportion of malnourished reduced 10 percent [6]. (According to Gross National Product of Madagascar, the proportion of the primary industry and the boost effect on the primary industry, we assume that the development scale increase 10 percent and the proportion of malnourished reduced 20 percent while investing 100 million dollars.) Each invested \$ 100 million to develop the first industrial scale increased by $10 \%$, the proportion of undernourished population decreased by 20\%)

Policy 4: Import food. Government provide 40 tons food every year free of charge, which can increase 0.8 year life of poverty people on average and increase 0.2 year life of national population on average. (According to the proportion of poverty people is provided by government, we assume that poverty people can get $0.1 \mathrm{Kg}$ food on average free of charge.)

Policy 5: Jobs and Job Trainings. 60,000 offers and trainings are provided, which can promote 2 percent of Per capita GDP. (We assume that the development of Madagascar follow the famous law: GDP increased by $2 \%$, unemployment is approximately $1 \%$, which was put forward by Arthur M. Okun who is an American economist.)

Policy 6: Provide Education. Education is divided into two modules. One is make the compulsory education become universal, namely invest 1500 million dollars every year, and provide a five-year compulsory education for all children. Another is try to popularize the higher education, namely increase publicity and incentive policies.

Policy 7: Provide Minimum Living Guarantee. In the first five-year the government provided 30.25 million dollars, to guarantee to provide 0.5 dollars subsidy to the people whose income is lower than 1.25 dollars. (According to the actual proportion of poverty people, we take only the people whose income is lower than 1.25 dollars into account.)

We create a 20 year sustainable development plan for Madagascar, similar to the thoughts of differentiation, we accomplish the plan a four-step process. When one step is finished, the plan will get a decay about 0.9 during the next step.

\section{The effect of the 20 Year Sustainable Development Plan on Madagascar}

The time series model is developed to predict the development in the next years. With the historical records, we can predict the figures in the near future, which is the data when our sustainable development plan is not constructed [7]. Then several figures are drawn about the comparison with and without the plan [8].
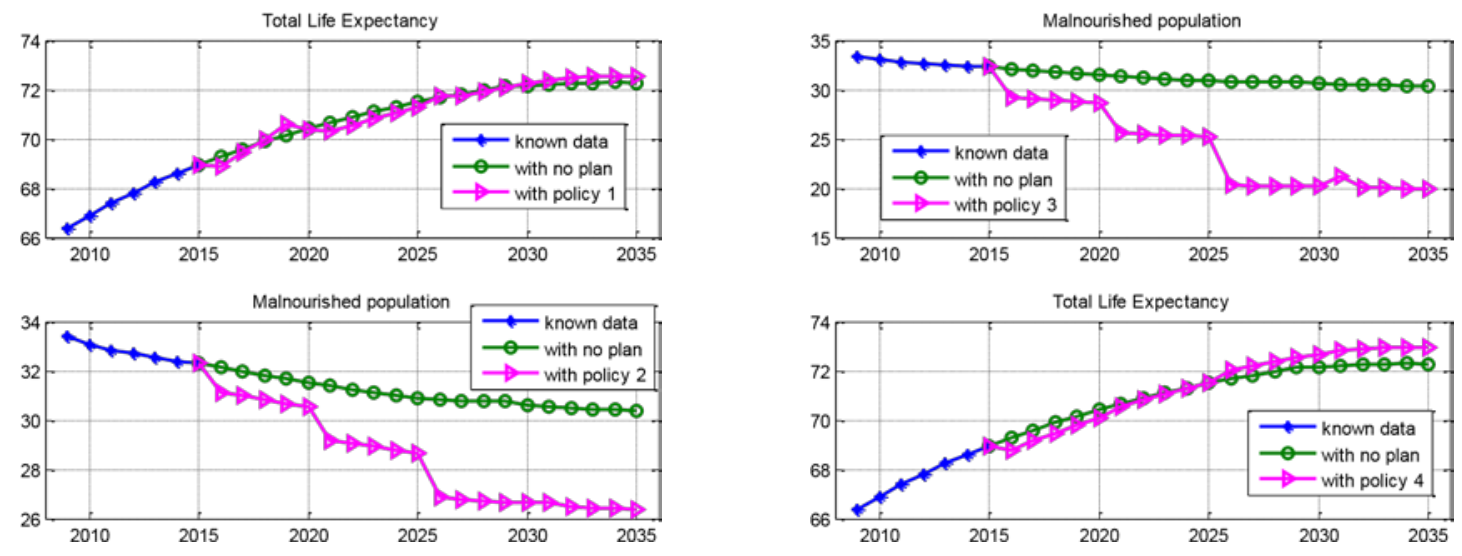
(a) Predict results of policy $1 \& 2$
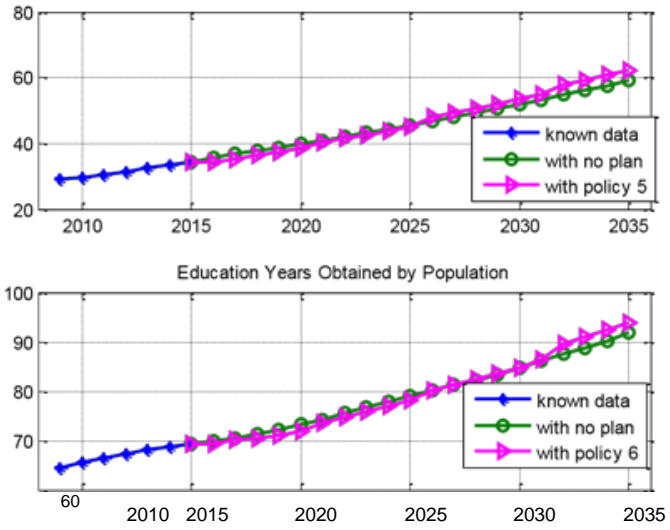

(c) Predict results of policy $5 \& 6$ (b) Predict results of policy $3 \& 4$
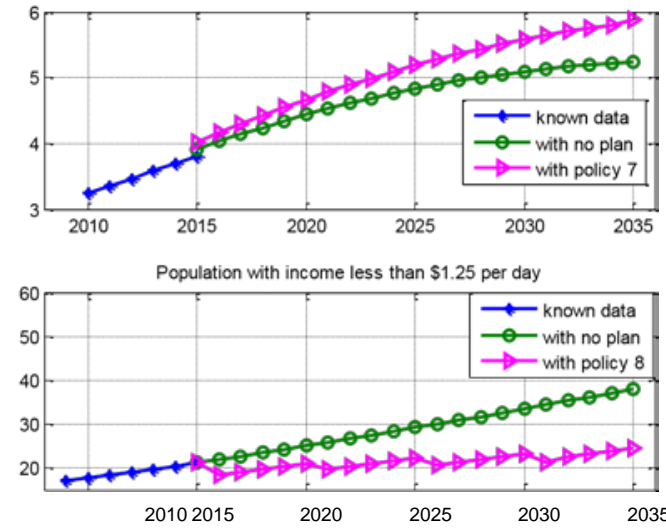

(d) Predict results of policy 7

Fig. 2 Predicted results of policy

We can clearly see from the above: the most efficient policies are polity2 and polity3, and the general efficient policy is polity7. So the conclusion is drawn that the best way to improve the sustainability of a country is investing medical capital and introducing advanced agricultural technologies.

\section{References}

[1] Yang Zhousheng. Environment and Human health [M]. Anhui Normal University Press, 2011.

[2] Cao Bin, Lin Jianyi, Cui Shenghui. Review on Assessment Index of Sustainable Development $[\mathrm{J}]$.

[3] Si Shoukui. Mathematical Modeling [M]. National Defend Industry Press, 2011.

[4] Pearce D W, Atkinson G D. Capital theory and the measurement of sustainable development: an indicator of "weak" sustainability [J]. Ecological economics, 1993, 8(2): 103-108.

[5] Ecosystems and human well-being [M]. Washington, DC: Island Press, 2005.

[6] Lindemann S. Madagascar Case Study: Analysis of National Strategies for Sustainable Development [J]. Unpublished working paper, 2004.

[7] Teng Wenxian. Study on Index System of Regional Sustainable Development Based on Analytic Hierarchy Process Method [D]. Tianjin University, 2009. 10

[8] http://info.worldbank.org/governance/wgi/index.aspx\#reports 11 